\title{
Application of time-of-flight aerosol mass spectrometry for the real-time measurement of particle-phase organic peroxides: an online redox derivatization-aerosol mass spectrometer (ORD-AMS)
}

\author{
Marcel Weloe and Thorsten Hoffmann \\ Department of Chemistry, Johannes Gutenberg University, 55128 Mainz, Germany \\ Correspondence: Thorsten Hoffmann (t.hoffmann@uni-mainz.de)
}

Received: 25 October 2019 - Discussion started: 8 November 2019

Revised: 20 July 2020 - Accepted: 28 July 2020 - Published: 28 October 2020

\begin{abstract}
Aerosol mass spectrometers (AMS) are frequently applied in atmospheric aerosol research in connection with climate, environmental or health-related projects. This is also true for the measurement of the organic fraction of particulate matter, still the least understood group of components contributing to atmospheric aerosols. While quantification of the organic and/or inorganic aerosol fractions is feasible, more detailed information about individual organic compounds or compound classes can usually not be provided by AMS measurements. In this study, we present a new method to detect organic peroxides in the particle phase in real-time using an AMS. Peroxides (ROOR') are of high interest to the atmospheric aerosol community due to their potentially high mass contribution to SOA, their important role in new particle formation and their function as "reactive oxygen species" in aerosol-health-related topics. To do so, supersaturated gaseous triphenylphosphine (TPP) was continuously mixed with the aerosol flow of interest in a condensation/reaction volume in front of the AMS inlet. The formed triphenylphosphine oxide (TPPO) from the peroxide-TPP reaction was then detected by an aerosol mass spectrometer (AMS), enabling the semiquantitative determination of peroxide with a time resolution of $2 \mathrm{~min}$. The method was tested with freshly formed and aged biogenic VOC and ozone SOA as well as in a short proof-of-principle study with ambient aerosol.
\end{abstract}

\section{Introduction}

Atmospheric aerosols attract attention in atmospheric research owing to their effects on climate and human health. The climate relevance of aerosol particles arises from their influence on the transmissivity of the atmosphere for solar radiation and on cloud properties (McNeill, 2017). Secondary organic aerosols (SOAs) are a major contributor to tropospheric particulate matter (Hallquist et al., 2009; Pöschl, 2005). One highly relevant class of compounds which is assumed to play an essential role in SOA formation, including participation in new particle formation, are organic peroxides (Bonn et al., 2004; Mochida et al., 2006; Reinnig et al., 2008, 2009; Tobias et al., 2000; Tobias and Ziemann, 2002; Zhou et al., 2018; Bianchi et al., 2016, 2017, 2019; Ziemann, 2002, 2003; Kahnt et al., 2018; Zhang et al., 2017; Lee et al., 2019). Besides their significant contribution to SOA mass (Docherty et al., 2005; Ziemann and Atkinson, 2012), particle-phase peroxides are especially interesting due to their often very low saturation vapor pressure, particularly when they contain several hydroperoxy groups induced by autoxidation (Tröstl et al., 2016; Krapf et al., 2016). Also their chemical properties such as their oxidizing character (Claflin et al., 2018) or their function as an indicator for the oxidizing capacity of the troposphere (Thompson, 1992; Lelieveld et al., 2008) create a special interest in the analysis of organic peroxides. Finally, peroxide functionalities are likely to play an important role in health-related effects of SOA, since organic peroxides are believed to contribute to the formation of reactive organic species (ROS) by transporting oxidants on and/or in particles 
into the respiratory system (Verma et al., 2015; Wragg et al., 2016; Fuller et al., 2014; Steimer et al., 2017; Tong et al., 2018).

The fact that organic peroxides are oxidizing agents is often used in their analysis. One of the oldest and most frequently applied techniques to measure and quantify peroxides is iodometry (Mertes et al., 2012; Docherty et al., 2005; Mutzel et al., 2013; Zhao et al., 2018). Alternatively, triphenylphosphine (TPP) can be used as a reacting agent. TPP rapidly reacts with hydrogen peroxide, organic (hydro)peroxides and peroxy acids to triphenylphosphine oxide (TPPO) (Docherty et al., 2004; Ruiz et al., 2001), which can be detected spectrometrically (Porter et al., 1979). There are various suggestions about the mechanism of the reaction. One of the mechanisms involves a bimolecular nucleophilic displacement of TPP on the $\mathrm{O}-\mathrm{O}$ bond resulting in a bipolar transition state (Eq. 1) (Jarvie et al., 1971; Chellamani and Suresh, 1988). Two other suggested mechanisms proceed via a cyclic peroxide intermediates (Eqs. 2 and 3) (Davies and Feld, 1958; Jayanthi and Koshore, 1997). The main application of the TPP-TPPO method is the determination of hydroperoxides from the autoxidation of oils and fats (Gotoh et al., 2011; Nakamura and Maeda, 1991; Wang et al., 2016). Compared to iodometric peroxide determination, the TPP-TPPO method is insensitive to moisture, and the reaction with oxygen is much slower.

Another technique that has been used for the analysis of organic peroxides is mass spectrometry (Krawczyk and Baj, 2014), for example for the measurement of SOA-related organic peroxides by direct infusion of liquid samples into an atmospheric-pressure chemical ionization tandem mass spectrometer (Zhou et al., 2018). However, all the abovementioned techniques are offline methods relying on filter sampling techniques, which have disadvantages such as the evaporation of semivolatile species or chemical alterations of labile compounds during sampling. Obviously the temporal resolution of offline methods is also limited. Therefore, online methods for organic peroxide measurements would be beneficial.

One of the main online techniques that is used in the field of aerosol research is the aerosol mass spectrometer (AMS), which is commercially available from Aerodyne Research Inc. (Billerica, MA, USA). Aerosol particles are introduced into a vacuum chamber through an aerodynamic lens that focuses the sampled aerosol particles to a beam (Jayne et al., 2000). The particle beam is directed onto an evaporation unit, which is heated to $600^{\circ} \mathrm{C}$, ideally volatilizing the entire particle mass. The evaporated compounds are subsequently ionized by electron ionization (EI) at $70 \mathrm{eV}$ and analyzed by MS (Pratt and Prather, 2012; Jayne et al., 2000). The application of EI allows the analysis of a wide range of chemical species and provides robust quantitative information on various nonrefractory ambient aerosol components since the ionization efficiency of EI is much less analyte and matrix dependent than, for example, chemical ionization techniques (Allan et al., 2003b, a; Canagaratna et al., 2007). However, EI induces a high degree of fragmentation of organic compounds due to excess internal energy imparted during the ionization processes. Usually, these fragmentation steps impede the identification and quantification of individual particle-phase organics, thus leading to a reduced level of chemical information (Zhang et al., 2011). Therefore, recent mass spectrometric instrumental developments for organic aerosol analysis focus on softer ionization techniques such as atmospheric pressure chemical ionization (APCI-MS) (Vogel et al., 2013b, a; Brüggemann et al., 2014; Warscheid and Hoffmann, 2001a, b), flowing atmospheric-pressure afterglow mass spectrometry (AeroFAPA-MS) (Brüggemann et al., 2015, 2016, 2017) or extractive electrospray ionization (EESI-MS) (Gallimore et al., 2017). However, while these mass spectrometric techniques are applicable for a wide spectrum of organic compounds and functionalities, for example, carboxylic acids (Hallquist et al., 2009; Yatavelli et al., 2015), unambiguous identification of organic peroxides using mass spectrometric techniques is still challenging, since in contrast to other functionalities the molecular ions usually fragment resulting from the cleavage of the peroxide bond and/or further fragmentation (Reinnig et al., 2009).

Here, we have combined the concept of selective peroxide determination by a suitable redox reaction (the TPPTPPO system) to use this reaction as an online derivatization method to monitor the educts and products with an aerosol mass spectrometer (online redox derivatization-AMS, ORDAMS). The development and application of the method presented in this paper is essentially a proof-of-principle study; however, the results clearly show the potential of online derivatization as an extension of regular AMS measurements, in this case for the understanding of particle-phase organic peroxides. Similar experimental setups with different derivatization agents are also conceivable in the future to further extend the usability of AMS systems.

\section{Experimental}

\subsection{Online redox derivatization}

Figure 1 shows a schematic diagram of the experimental setup for the AMS online measurements. Gas-phase organics were firstly removed by two charcoal-filled denuders (inner tube: diameter $=2 \mathrm{~cm}$ and length $=40 \mathrm{~cm}$; outer tube: diameter $=13.5 \mathrm{~cm}$, length $=40 \mathrm{~cm}$ ), and the particle size distribution was measured using a scanning mobility particle sizer (SMPS; Grimm Aerosol Technik, Ainring, Germany).

When the instrument was used in the ORD-AMS mode (blue path in Fig. 1) the particles to be analyzed were introduced into a $500 \mathrm{~mL}$ glass tube $(35 \mathrm{~cm}$ length; $4.5 \mathrm{~cm}$ max. diameter ), the condensation/reaction volume. Here, the aerosol was mixed with the gaseous reactant (TPP; 99\%, Acros Organics BVBA, Geel, Belgium), which was supplied 

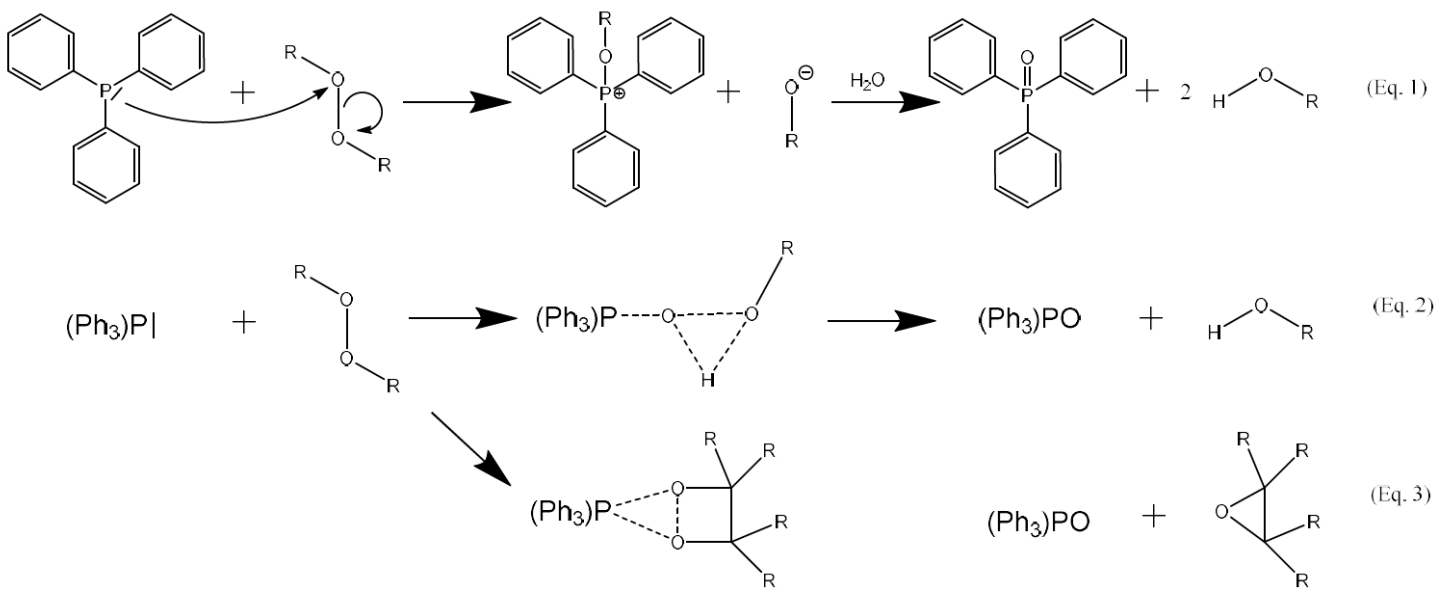

$\begin{array}{ll}\text { Triphenylphosphine (TPP) } & \mathrm{R}=\text { hydrogen, alkyl, acyl } \\ \text { MW } 262 \mathrm{~g} \mathrm{~mol}^{-1} & \mathrm{R} \neq \text { tert-alkyl }\end{array}$

Triphenylphosphine oxide (TPPO)

MW $278 \mathrm{~g} \mathrm{~mol}^{-1}$

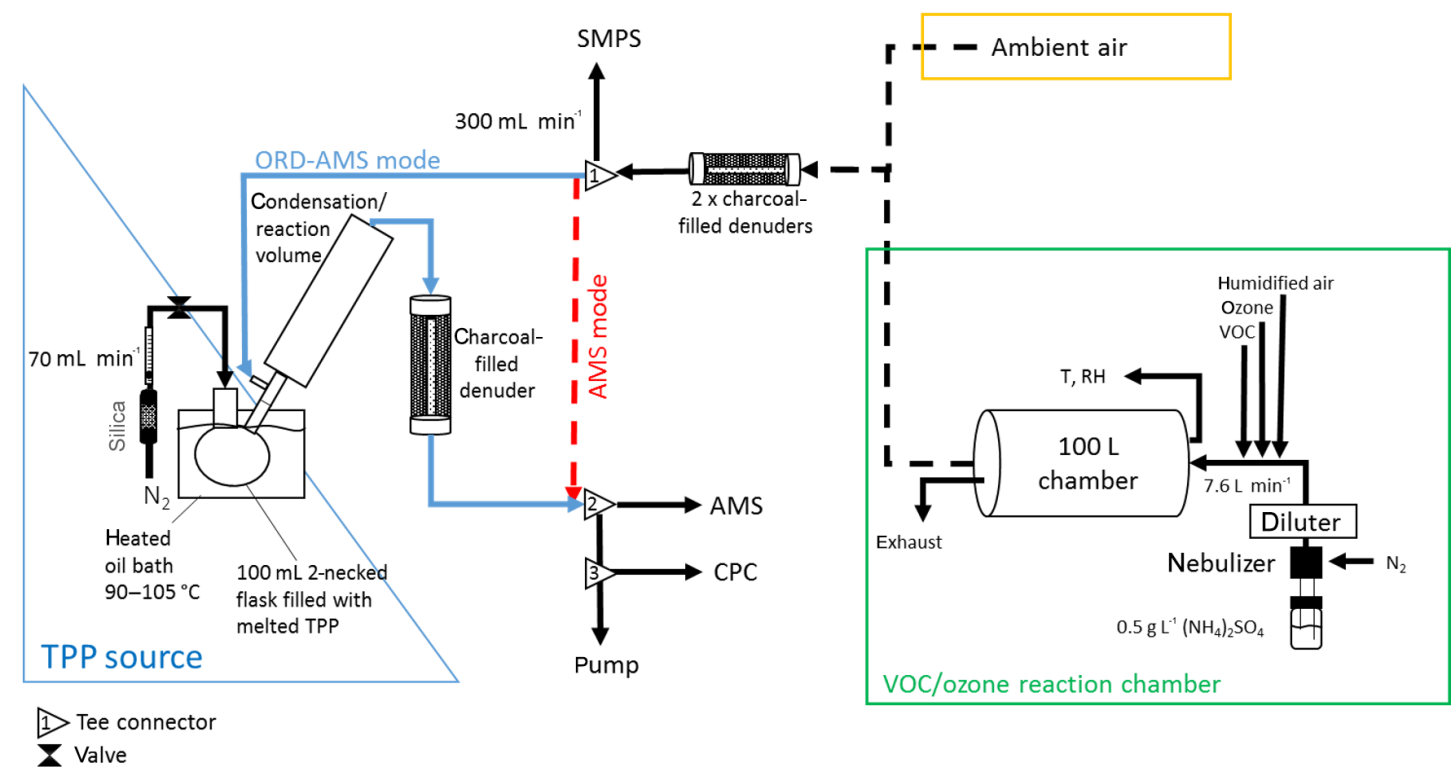

Figure 1. Experimental setup: the aerosol is either generated with a $100 \mathrm{~L}$ reaction chamber via VOC- $\mathrm{O}_{3}$ reaction, usually also introducing AS seed particles, or supplied from outside of the chemistry building. The aerosol is then led to the aerosol mass spectrometer, either directly (AMS mode, red arrow) or through the online derivatization unit (ORD-AMS mode) in which the test aerosol is mixed with a nitrogen stream containing supersaturated gaseous TPP. Remaining gaseous TPP is removed by charcoal-filled denuder after the condensation/reaction volume. Most of the time the aerosol is characterized by the ToF-AMS, an SMPS system and a CPC.

from a Sinclair-La Mer setup (see Fig. 1, blue triangle). The TPP source consisted of a $100 \mathrm{~mL}$ two-necked, round-bottom glass filled with TPP and was heated to a temperature of $90^{\circ} \mathrm{C}$. Nitrogen was used as a carrier gas to deliver the TPP to the condensation/reaction volume, where TPP condensed on the available particle surface. After passing the condensation/reaction volume the aerosol was led through a third denuder filled with active charcoal to remove gas-phase TPP and finally introduced into the AMS and a condensation particle counter (CPC; PortaCount Plus, TSI Inc., Shoreview, MN, USA). A total flow rate of $1.74 \mathrm{~L} \mathrm{~min}^{-1}$ was obtained using an additional pump. The residence time of the aerosol in the reaction volume and the denuder to the AMS was about $35 \mathrm{~s}$.

When the instrument was used in the AMS mode (red path in Fig. 1), the aerosol was led directly to the AMS and the CPC. Switching between the two modes was achieved by manually changing the PTFE connections to avoid losses or artifacts from additional valves. The data acquisition of the AMS and SMPS was interrupted during this time and continued (1-2 min) after stabilization of the particle number concentration measured by the CPC. As mentioned above, a ni- 
trogen stream enriched with TPP was added to the aerosol stream in the ORD-AMS mode, resulting in a dilution of the aerosol. The correction for this dilution was done by comparing the particle number concentrations, measured in the ORD-AMS and AMS mode using the CPC. The ratio between the particle number concentrations of the two modes was used as a dilution factor.

\subsection{ToF-AMS}

The aerosol particles were introduced into the time-of-flight (ToF)-AMS (Aerodyne Research Inc., Billerica, MA, USA) at a sampling flow rate of $1.23 \mathrm{~mL} \mathrm{~s}^{-1}$. An aerodynamic lens system focuses the particles in a size range of $\sim 35-1000 \mathrm{~nm}$ into the vacuum system. While most of the remaining gas phase is removed, the particle beam passes into the particlesizing chamber. The ToF-AMS was either operated in the mass spectrum (MS) or the particle time-of-flight (PToF) mode. The first mode provides information about the overall composition of the total aerosol mass without any information about the particle size, while the second mode results in the size-segregated analysis of the particle composition. For the latter one, a chopper allows the transmission of only a small part of the aerosol into the PToF chamber. Due to increasing inertia with larger particle size, the particle package is separated by the particles' time of flight, and the size distribution based on the mean vacuum aerodynamic diameter of the aerosol can be determined. In this PToF mode, the EI-ToF-MS functions as a detector for the particle time of flight. To determine the concentration in the MS mode, the beam passes the chopper alternately blocked or unblocked for background corrections. After passing the particle-sizing chamber, the aerosol particles are vaporized on a heated porous tungsten surface at $600^{\circ} \mathrm{C}$, followed by immediate ionization in electron impact (EI) mode at $70 \mathrm{eV}$. The generated ions are extracted by an orthogonal extractor into the ToF-MS, which was operated in the $\mathrm{V}$ mode to give higher sensitivity. The MS spectra acquisition was performed in the positive ion mode. The AMS data were processed by the Igor (Version Pro 6.37)-based programs "SQUIRREL 1.57 G" (unit mass resolution) and "PIKA 1.16H" (high resolution) (DeCarlo et al., 2006; Canagaratna et al., 2007).

\subsection{Physical aerosol characterization and generation}

A scanning mobility particle sizer was used to measure the size distributions of the particle number concentration of the incoming aerosol, which was used to obtain particle surface, volume and mass concentration. The conversion of the volume concentration into the mass concentration for the ozonolysis experiments is described in detail in the Supplement. Besides the measurement of the particle size distribution, the instrument was used to generate monodisperse particles for instrument calibration. The EI spectra of the derivatization agent TPP and its reaction product with per- oxides TPPO (> $98 \%$, Merck KGaA, Darmstadt, Germany) were recorded using a nebulizer as a particle generator. Pure TPP and TPPO particles were produced from solutions in methanol (Optima ${ }^{\circledR}$ LC/MS grade, Fisher Scientific, Loughborough, UK) and $n$-heptane (HPLC grade, Carl Roth GmbH + Co. KG, Karlsruhe, Germany), respectively. For these experiments, the particles were size-selected using a differential mobility analyzer (DMA) in a setup described in the Supplement.

\subsection{Reaction chamber as SOA generator}

For the proof-of-principle studies with SOA, a laboratoryscale reaction chamber in continuous-flow tank reactor mode was used. Synthetic air was supplied with a total flow of $7.6 \mathrm{~L} \mathrm{~min}^{-1}$ into the $100 \mathrm{~L}$ chamber, resulting in a residence time of $13.5 \mathrm{~min}$. The total flow was composed of a gas stream through a diffusion test gas source (Thorenz et al., 2012) (0.600 $\left.\mathrm{L} \mathrm{min}^{-1}\right)$, where the VOC of interest was added to the synthetic air supply. A second gas stream $\left(2.6 \mathrm{~L} \mathrm{~min}^{-1}\right)$ was humidified using a gas-washing bottle, and a third gas flow was led through an ozone generator (Dasibi Environmental Corp. Model 1008 RS O3 analyzer, Glendale, CA, USA; $2.7 \mathrm{~L} \mathrm{~min}^{-1}$ ). To add seed particles an aqueous solution of ammonium sulfate (ca. $0.5 \mathrm{~g} \mathrm{~L}^{-1} ;>99.5 \%$, Merck KGaA, Darmstadt, Germany) was nebulized using technical nitrogen and introduced into the chamber $\left(1.7 \mathrm{~L} \mathrm{~min}^{-1}\right)$. Temperature and relative humidity were $25^{\circ} \mathrm{C}$ and $61 \%$ for the $\alpha$-pinene ozonolysis and $22^{\circ} \mathrm{C}$ and $59 \%$ for the $\beta$-pinene ozonolysis. They were monitored by a thermo-hygrometer (Amarell, ama-digit ad $910 \mathrm{~h}$, Kreuzwertheim, Germany). The chamber was set to be under slight overpressure to prevent the entry of laboratory air into the setup. The reaction chamber was wrapped with aluminum foil to avoid photochemical reactions. For the ozonolysis of $\alpha$-pinene (99\%, Fluka, Seelze, Germany), the chamber was first equilibrated with the terpene before the ozone generator was switched on. For the $\beta$-pinene $(99 \%$, Sigma Aldrich Chemie GmbH, Steinheim, Germany) experiments, the order of the addition of the individual compounds was reversed - i.e., ozone was added before the terpene. The ozone concentration was estimated to be about $1 \mathrm{ppm}$, while the $\alpha$-pinene concentration was set to $290 \mathrm{ppbv}$ and the $\beta$-pinene concentration to $380 \mathrm{ppbv}$. To remove gaseous organic compounds, the SOA formed in the reaction chamber was led through two diffusion denuders filled with activated charcoal.

\section{Results and discussion}

\subsection{EI mass spectra}

Figure 2 shows the obtained mass spectra of TPPO and TPP. The EI spectra of the two reference compounds measured by the AMS are very similar to the spectra measured by the regular MS setup (Williams et al., 1968; Stein and Slaw- 


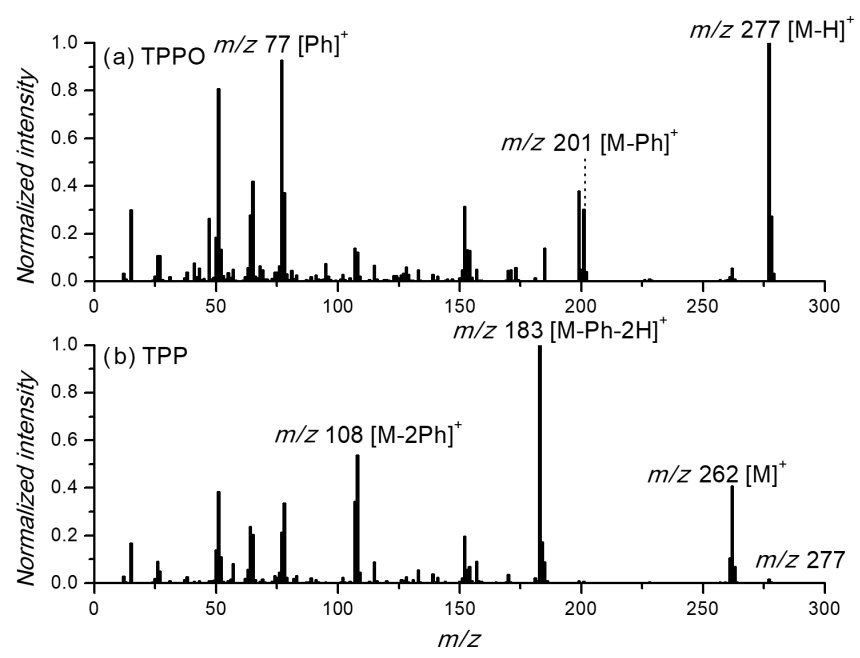

Figure 2. Mass spectra of (a) triphenylphosphine oxide (TPPO) and (b) triphenylphosphine (TPP).

son, 1963). The base peak for TPPO is at $m / z 277$ resulting from a hydrogen abstraction, $[\mathrm{M}-1]^{+}$, from the molecular ion - molar weight MW $\left.(\mathrm{TPPO})=278 \mathrm{~g} \mathrm{~mol}^{-1}\right)$. The second-largest peak is $m / z 77$ formed from the abstraction of a phenyl cation. The base peak for TPP is located at $m / z$ 183, originating from the abstraction of two hydrogens and a phenyl group, probably a result of an aromatic stabilization of the resulting dibenzophosphole cation (Williams et al., 1968). However, the molecular ion of TPP at $m / z 262$ is also visible. More important is the small but still observable $[\mathrm{M}-1]^{+}$ion of TPPO in the TPP spectra. Since the peroxide determination is based on the measurement of TPPO, this background signal has to be taken into account (see below). Finally, aerosol species typically found in ambient air and measured by the AMS have mass spectra with signals mainly below $m / z 100$ due to the fragmentation after EI ionization. As seen also in Figs. S4 and S5 in the Supplement, the signals at $m / z 277$ and 262 are specific for TPPO and TPP, respectively. These signals can be used for the quantification of both compounds.

Experiments with peroxides (ROOR') as reference compounds were also performed, using commercially available organic peroxides, e.g. lauryl peroxide and benzoyl peroxide. While these experiments clearly showed the formation of TPPO from TPP, the use of these compounds for quantification was not possible, since the peroxide standards studied undergo a substantial change in volatility after the reaction with TPP. Therefore, lauryl peroxide and benzoyl peroxide were used to demonstrate the general proof of feasibility of the method but not, however, for calibration.

\subsection{Quantification}

The mass concentration $c_{\mathrm{m}}$ of a single compound measured by an AMS can be expressed as (Canagaratna et al., 2007)

$c_{\mathrm{m}}=\frac{10^{12} \cdot \mathrm{MW}(\text { compound })}{\mathrm{IE}(\text { compound }) \cdot Q \cdot N_{\mathrm{A}}} \cdot \sum_{\text {all }, i} I_{\text {compound }, i}$,

where MW and IE are the molar weight and the ionization efficiency of an individual compound, respectively. The ionization efficiency (IE) is a dimensionless quantity that describes the ionization and detection efficiency and is defined as the ratio of the ions detected to the parent molecules vaporized. $Q$ is the flow rate into the AMS, $N_{\mathrm{A}}$ Avogadro's number and $10^{12}$ a unit conversion factor. $I_{\text {compound }, i}$ is the ion rate of an ion $i$ formed by ionization and fragmentation of a compound. Since the fragmentation pattern can be assumed to be robust, it is possible to use the ion yield of a single ion $I_{m / z, i}$ to calculate the concentration. Based on the stoichiometry of the reaction, the molar concentration $c_{n}$ of peroxides is the same as the concentration of TPPO and can be calculated from the signal at $m / z 277$ as

$$
\begin{aligned}
& c_{n}(\mathrm{TPPO})=\frac{10^{12}}{\mathrm{IE}\left(\mathrm{TPPO}, \frac{m}{z} i\right) \cdot Q \cdot N_{\mathrm{A}}} \cdot I_{\frac{m}{z}} i \\
& c_{n}(\mathrm{TPPO})=\frac{10^{12}}{\mathrm{IE}\left(\mathrm{TPPO}, \frac{m}{z} 277\right) \cdot Q \cdot N_{\mathrm{A}}} \cdot I \frac{m}{z} 277 \\
& c_{n}(\mathrm{TPP})=\frac{10^{12}}{\mathrm{IE}\left(\mathrm{TPPO}, \frac{m}{z} 262\right) \cdot Q \cdot N_{\mathrm{A}}} \cdot I \frac{m}{z} 262 .
\end{aligned}
$$

The experimental procedure to estimate IE is discussed in more detail in the Supplement.

\subsection{Background correction}

As mentioned above (see Sect. 3.1) TPP particles, as well as pure ammonium sulfate aerosol particles passing the TPPcondensation/reaction chamber, also show a small but nonnegligible TPPO signal $(\mathrm{m} / \mathrm{z}, 277)$. This is either a consequence of TPPO impurities in the TPP itself or due to traces of peroxides in the solvents used to generate the aerosol particles when the nebulizer was used. Consequently, a background correction procedure has to be introduced to account for these effects. To do so, pure ammonium sulfate (AS) aerosol particles were investigated with different initial ammonium sulfate concentrations with the ORD-AMS setup as described above. These experiments showed a constant background contribution of $1.2( \pm 0.1) \%$ TPPO resulting from the conversion of TPP $\left[\mathrm{m} / z 262 \Rightarrow C_{n}\right.$ (detected TPP)]. Therefore, the concentration of the analyte of interest $\left[C_{n}\right.$ (perox- 
ide)] was calculated as follows:

$$
\begin{aligned}
& c_{n}(\text { backgr. TPPO })=0.012 \cdot c_{n}(\text { detected TPP }) \\
& c_{n}(\text { produced TPPO })=c_{n}(\text { detected TPPO }) \\
& -c_{n} \text { (backgr. TPPO) } \\
& c_{n}(\text { peroxide })=c_{n}(\text { produced TPPO }) \text {. }
\end{aligned}
$$

\subsection{SOA experiments}

The ozonolysis of $\alpha$ - or $\beta$-pinene was performed in the presence of ammonium sulfate (AS) seed particles, and the results of a typical chamber run with $\alpha$-pinene are shown in Fig. 3. First, AS seed particles were injected into the chamber. After a certain period of time, when the particle concentration became constant, the biogenic VOC was introduced into the chamber (e.g., after $34 \mathrm{~min}$ in the run shown in Fig. 3). Following an initial period to monitor background peroxide concentrations in the AS seed aerosol-VOC system, ozone was introduced (e.g., after $135 \mathrm{~min}$ in the $\alpha$ pinene run shown in Fig. 3, green area). Periods when TPP was not added (AMS mode in Fig. 1) are marked in grey and were used to determine the dilution factor and the concentration of SOA by the AMS. As can be seen in the figure, the concentrations of both TPPO and TPP rose quickly during the first 20-25 min after the ozone addition (Fig. 3a), followed by a slow decrease towards the end of the experimental run. Why the TPP signal also rises will be explained below. However, peroxides were only detected when SOA formation began, as indicated by the time series of peroxide concentration (Fig. 3b, black) and SOA mass concentration (Fig. 3b, blue line). Figure 3c shows the temporal behavior of the relative contribution of peroxides to SOA, whereby an average molar mass of $250 \mathrm{~g} \mathrm{~mol}^{-1}$ for SOA was assumed. The course of the peroxide quantity per SOA quantity (Fig. 3c) shows a continuous decrease during the entire experimental run. Such concentration profiles of the organic peroxides are indicative of consecutive reactions, in which the peroxides are formed as first-generation products form the initial ozone/alkene reaction in the gas phase, followed by gas-toparticle conversion and further reactions of the peroxides to non-peroxidic products in the particle phase. Indeed, several studies suggest that organic peroxides are instantly formed in the VOC-ozone reaction (Bianchi et al., 2019; Mertes et al., 2012) and the rapid increase of the peroxide signal as shown in Fig. $3 b$ confirms these studies. However, since the $\mathrm{O}-\mathrm{O}$ bond is relatively weak, organic peroxides tend to decompose or react with other aerosol components. Possible reactions to non-peroxidic products could be reactions with alcohols or aldehydes forming aldehydes or carboxylic acids, or hydrolysis followed by the loss of $\mathrm{H}_{2} \mathrm{O}_{2}$ (Zhao et al., 2018; Claflin et al., 2018; Epstein et al., 2014). In any case, the temporal evolution of the peroxide concentration (i.e., the formation/decline profile) indicates consecutive reactions and demonstrates the intermediate character of the peroxides within the VOC oxidation system.
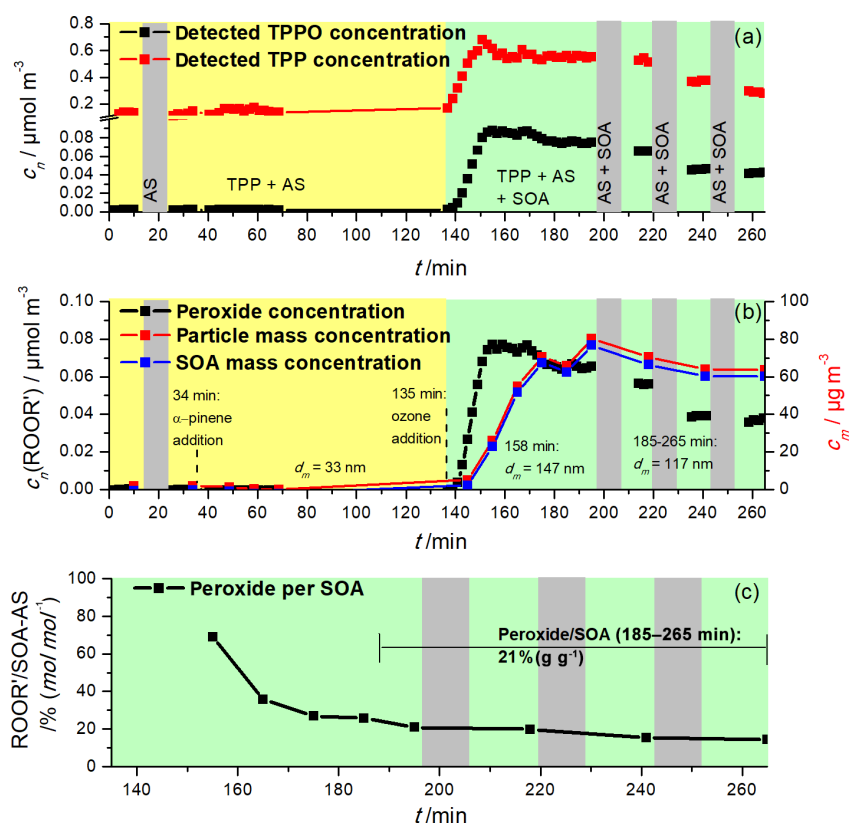

Figure 3. Time series of (a) the detected TPPO (black) and detected TPP (red), (b) the peroxide concentration (black) after background correction and particle mass concentration of the SOA-AS aerosol (red) and the SOA (blue), and the (c) relative contribution of peroxide to the total aerosol volume (black; time resolution $10 \mathrm{~min}$ ). Periods without the addition of TPP (AMS mode) are marked with a grey background; the period before the addition of ozone is marked in yellow and during the ozonolysis in green (with TPP, ORD-AMS mode). $\alpha$-pinene was continuously added after $34 \mathrm{~min}$ and ozone after $135 \mathrm{~min}$.

As can be seen in Fig. 3c, the contribution of peroxides to SOA was almost $70 \%$ after about $20 \mathrm{~min}$. During the last $80 \mathrm{~min}$ of the experiment, the SOA concentration was about $69 \mu \mathrm{g} \mathrm{m}^{-3}\left(0.28 \mu \mathrm{mol} \mathrm{m}{ }^{-3}\right)$, assuming again an average molar mass of the SOA components of $250 \mathrm{~g} \mathrm{~mol}^{-1}$. During this time the measured peroxide concentration was about $0.0470 \mu \mathrm{mol} \mathrm{m}{ }^{-3}$. Paul Zieman and coworkers (Docherty et al., 2005) proposed an average molar mass of $300 \mathrm{~g} \mathrm{~mol}^{-1}$ for SOA peroxides. Based on this value the average peroxide mass concentration was $14.1 \mu^{-3} \mathrm{~m}^{-3}$, assuming the same density of peroxides as for other SOA components (1.2 $\mathrm{g} \mathrm{cm}^{-3}$; Kuwata et al., 2012). Thus the average peroxide/SOA yield within this period is estimated to be about $20 \%( \pm 4 \%)$. Actually, this value is very close to the value of $22 \%$ (Epstein et al., 2014) or the value of $21 \%$ (Li et al., 2016). Mertes and coworkers (Mertes et al., 2012) observed $34 \%, 17 \%$ and $12 \%$ for $15-35 \mathrm{~min}, 4 \mathrm{~h}$ and $6 \mathrm{~h}$ filter samples, respectively. Taking into account the influence of sampling time, duration of sampling, initial ozone and terpene concentrations as well as temperature and relative humidity, these values agree quite well.

As can be seen in Fig. 3a, the TPP concentration also increased after the start of ozonolysis. This is understandable, 
considering that TPP is only detected by the AMS when it condenses on particles. The more particles are introduced into the ORD setup, the higher the TPP concentration measured by the AMS. Figure 4 shows the particle size distribution measured by the SMPS system before (black) and within the first 10 min after (red) ozone was introduced into the reaction chamber. Despite the presence of AS seed particles, new particle formation from nucleation of organic compounds was observed, resulting in a bimodal size distribution at the beginning of the experiment. In principle, new particle formation is not surprising due to the high particleformation potential of biogenic VOCs as well as the relatively high concentrations of the reactants. The same behavior was also visible in the AMS data. One of the main advantages of the AMS is the possibility to determine the size distributions of individual compounds. If the $m / z$ is characteristic for an aerosol component, such as $m / z \quad 30$ and 46 for nitrate, for example, the size distribution of these components can be obtained. Figure 5 shows the $m / z$ values as a function of particle size for TPP $(\mathrm{m} / z$ 262; blue), TPPO $(\mathrm{m} / z$ 277; black), SOA ( $m / z$ 43; green) and sulfate (red) for the first $10 \mathrm{~min}$ after ozone was introduced, all normalized to the respective maximum value. Although the determined size distributions by SMPS and AMS are not identical, likely due to scanning time effects, differences in aerodynamic and mobility diameters as well as differences in the averaging procedure, the bimodal size distribution of pure organic particles and pre-existing AS-containing particles is also visible in the AMS data. While the occurrence of organic nucleation simultaneously with condensational growth resulting in two externally mixed particle populations is not surprising, a more quantitative description of the size distribution of selected compound groups is challenging. As can be seen in Fig. 5, the size profiles of SOA and TPPO are very similar, with a clear preference for the smaller particle sizes. Besides the obvious explanation of the existence of a pure organic particle population formed by homogeneous nucleation, an additional explanation is a size-dependent condensation of the organics also on the inorganic seed particles. A unique characteristic of condensational growth is that it is proportional to the Fuchs-corrected surface area of particles and not the particle volume - "surface-limited" vs. "volume-limited" growth. Because the surface area to volume ratio of particles increases as their diameter decreases, condensation tends to have a larger effect on smaller particles. Therefore, after the condensational growth of AS seed particles, the final distribution of the condensed organics can be expected to favor the smaller particles (Donahue et al., 2014; Riipinen et al., 2011). Therefore, both nucleation of organics and condensational growth will contribute to the size distribution shown in Fig. 5. Nevertheless, the results clearly show that the formation of peroxidic compounds is directly connected to SOA formation. More difficult to explain is the quite similar size distribution of TPP and ammonium sulfate seed aerosol since TPP also moves to the particle phase via condensation. One

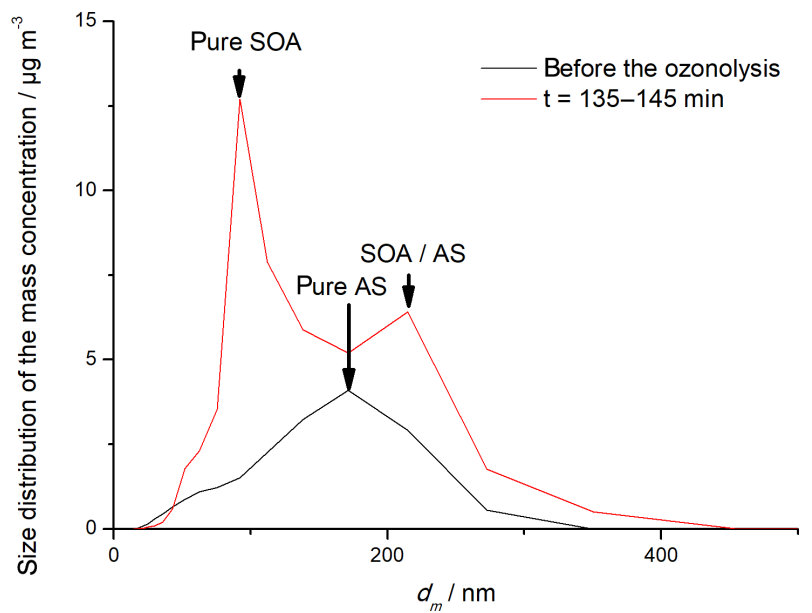

Figure 4. Particle mass size distribution before and 10 min after the addition of ozone.

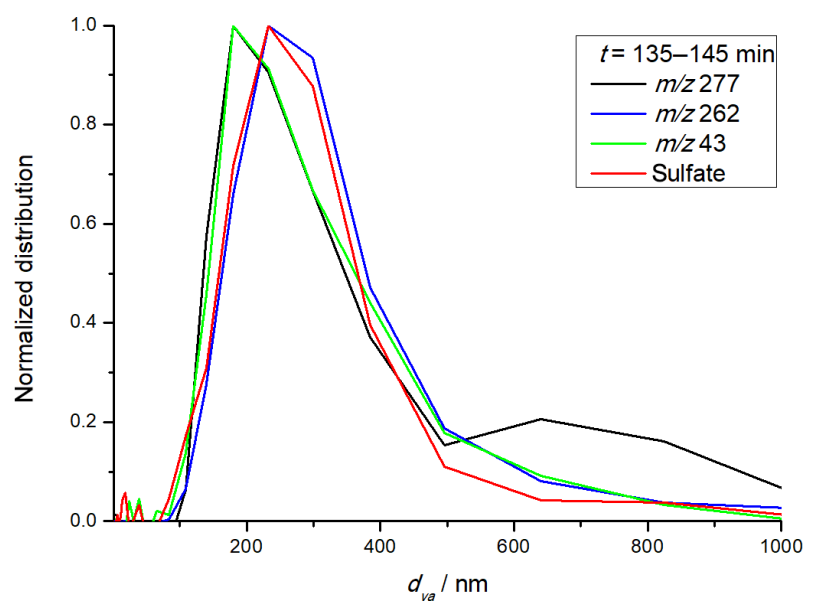

Figure 5. Size distribution of individual particle-phase compounds (TPPO, TPP, SOA, sulfate) within the first 10 min after the addition of ozone.

possible explanation could be attractive forces between the nonpolar TPP molecules and AS, similar to a "salting in" effect (Hyde et al., 2017). However, possibly other effects, such as the high supersaturation of TPP in the condensation/reaction volume, also might be considered to explain the observations.

Figure 6a-d show the size distributions of $m / z 277$ (black), 262 (blue), 43 (green) and sulfate (red) for the periods before $(\mathrm{a}, \mathrm{b})$ and during $(\mathrm{c}, \mathrm{d})$ the last $80 \mathrm{~min}$ of the ozonolysis, with (b, d) and without $(a, c)$ added TPP. Again, each of the individual ratios is normalized to its respective maximum; $m / z 262$ corresponds to the detected TPP, $m / z 277$ to TPPO and $m / z 43$ to SOA species (see Fig. S6 in the Supplement). Figure 6a shows the size distribution of pure AS particles. As can be seen, by comparison of Fig. 6a and $b$, the diameter of sulfate remained almost constant due to the condensation of TPP - if anything then the diameter 
(a) Without TPP, before the ozonolysis

(b) With TPP, before the ozonolysis
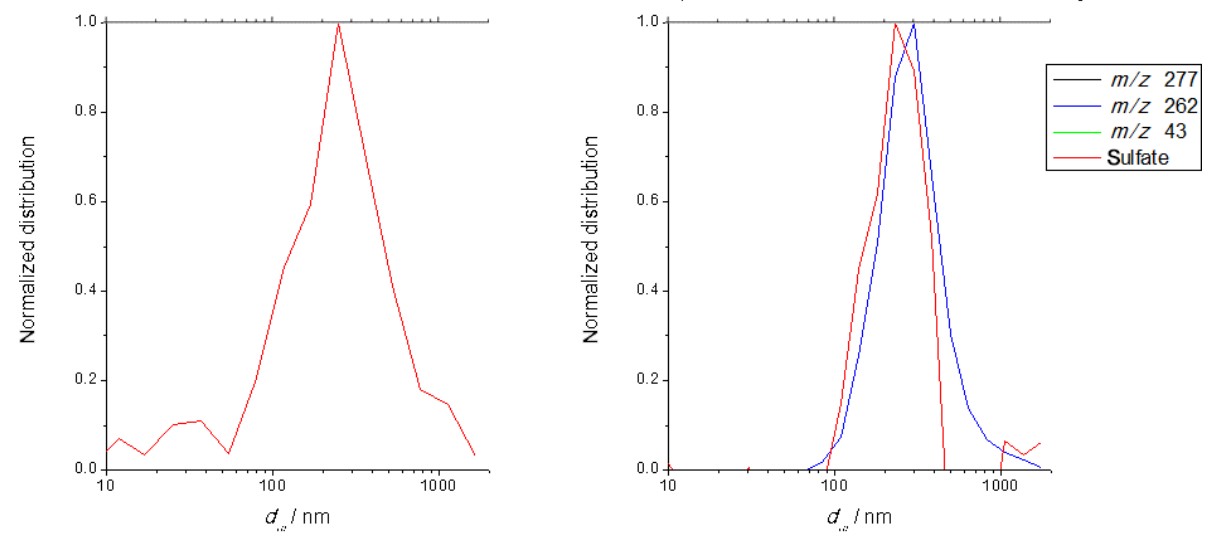

(c) Without TPP, end of the ozonolysis

(d) With TPP, end of the ozonolysis
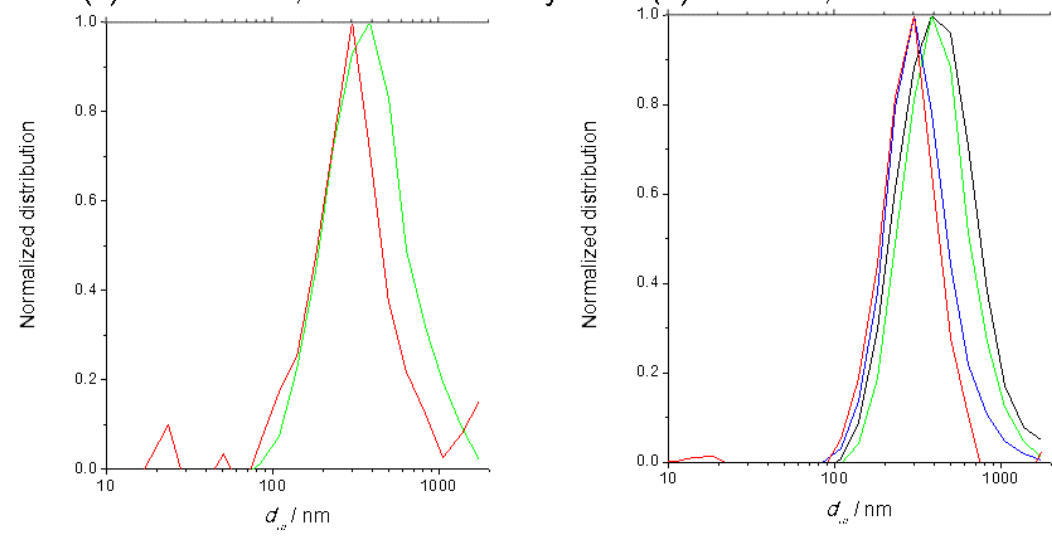

Figure 6. Size distribution of $m / z 277$ (black is TPPO), $m / z 262$ (blue is residual TPP), $m / z, 43$ (green is SOA) and sulfate (red) for following periods: before the start of the ozonolysis (a) without and (b) with adding TPP and at the end (185-265 min) of the ozonolysis (c) without and (d) with adding TPP. All distributions were normalized to their respective maximum.

slightly decreased. Generally, the vacuum-aerodynamic diameter depends on the particle density (DeCarlo et al., 2004). The larger the density, the larger $d_{\mathrm{va}}$ is for particles with the same physical diameter. The condensation of TPP (density: $1.1 \mathrm{~g} \mathrm{~cm}^{-3}$ ) will lower the particle density (density of AS: $1.77 \mathrm{~g} \mathrm{~cm}^{-3}$ ), which compensates for the increase in the physical diameter. Nevertheless, the condensation of SOA material finally led to an increase in the sulfate diameter (Fig. 6c). In Fig. 6d the size distributions of the four different components are shown. First to notice is again the clear overlap of $\mathrm{m} / z 277$ and $\mathrm{m} / \mathrm{z} 43$, demonstrating the simultaneous presence of TPPO and SOA species in the particle phase. The slight shift in the size distribution to larger sizes for SOA $(m / z 43)$ and TPPO is likely a result of slightly faster growth of the pure organic particles formed by nucleation as discussed above compared to the ammoniumsulfate-containing particles.

A second biogenic VOC, $\beta$-pinene, was investigated with the online redox derivatization-AMS system, this time with a reverse introduction of the VOC and the oxidant to examine ozone as a direct oxidant for TPP. Again, the ozonolysis of $\beta$-pinene was performed in the presence of AS seed aerosol. Figure 7 shows the temporal evolution of the peroxide concentration together with the total aerosol mass concentration determined with the SMPS. As in the case of $\alpha$ pinene, the peroxide concentration increased rapidly with the formation of SOA, once again demonstrating the direct connection of SOA and peroxide formation via the detection of TPPO. The comparison of the profiles of SOA (blue) and peroxide (black) demonstrates the very rapid peroxide formation followed by the decreasing contribution of peroxides to the particle phase in the later stages of the experiment as a consequence of consecutive reactions of the peroxides to nonperoxidic products. The strong decrease in total SOA after $240 \mathrm{~min}$ is induced by the end of $\beta$-pinene addition to the reaction system. The observed shift between the peroxide and SOA concentration supports the concept of organic peroxides as reaction intermediates, which contribute especially to the composition of fresh SOA and convert to non-peroxidic products in aged SOA particles. This is also clearly visible in Fig. $7 \mathrm{~b}$, which shows the relative contribution of peroxides to the total particle volume in the course of the experiment. However, most important for the overall method evaluation are the very low and rather constant TPPO concentrations 

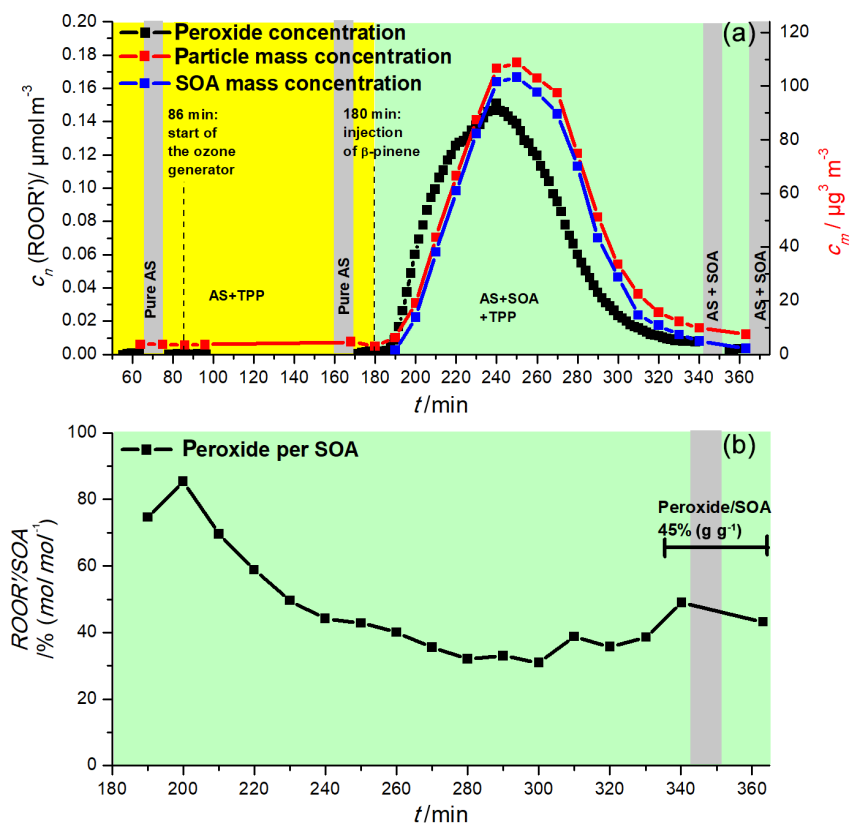

Figure 7. Ozonolysis of $\beta$-pinene in the presence of AS aerosol. Time series of (a) peroxide (black), particle mass concentration (red) and SOA mass concentration (blue); (b) relative contribution of peroxide to the amount of SOA. Ozone was added at $86 \mathrm{~min}, \beta-$ pinene at $180 \mathrm{~min}$. Averages molar masses of 250 and $300 \mathrm{~g} \mathrm{~mol}^{-1}$ for SOA and peroxides were assumed, respectively.

in the period between the ozone and $\beta$-pinene addition (between $86 \mathrm{~min}$ and $180 \mathrm{~min}$ ) when just AS particles were introduced into the ORD-AMS system, a result that clearly excludes ozone as a direct oxidant for TPP.

\subsection{Discussion}

As discussed above, the validation of the quantitative performance of the presented measurement method was not performed with peroxide reference compounds. Instead, the ratio between the concentration of peroxides and total SOA at the end of the ozonolysis of $\alpha$-pinene was compared with the results of Epstein et al. (2014), Li et al. (2016) and Mertes et al. (2012). In these studies the peroxide concentration formed from the ozonolysis of $\alpha$-pinene using filter or impactor sampling, followed by the extraction and iodometric analysis of the peroxide content, was measured. Several experimental parameters, such as the terpene and ozone concentration, their ratio to each other, the temperature, and the relative humidity, were slightly different. However, the comparison show very good agreement with values close to $20 \%$. Another aspect of all SOA experiments which include chemistry, as the peroxide-TPP reaction here, that has to be considered is the question of the phase state of SOA. According to Koop et al. (2011) SOA is expected to be a liquid under the conditions used for our experiments $\left(22-25^{\circ} \mathrm{C}\right.$; RH $\left.60 \%\right)$. Under these conditions also the AS seed particles can be ex- pected to have liquid-like behavior (Matthew et al., 2008). As a consequence, the diffusion time of TPP within the particles should be approximately $1 \mathrm{~s}$ (Koop et al., 2011), which is much shorter than the residence time of about $35 \mathrm{~s}$ of the aerosol in the ORD setup (Fig. 1). In conclusion, based on the agreement of the peroxide/SOA ratio at a later stage of the experiments measured in this work and the results of former studies, the estimated diffusion times and the excess of the reactant TPP to SOA, a quantitative reaction of TPP with the particle-phase peroxides to TPPO can be assumed. However, in future investigations, the method should be revalidated using as aerosol particles composed of pure single-component peroxides.

\subsection{Ambient air measurements}

Finally, the ORD-AMS method was tested with ambient air directly outside the chemistry building located at the campus of the university in Mainz $\left(49.9915928^{\circ} \mathrm{N}, 8.2312864^{\circ} \mathrm{E}\right.$ ). The measurements were performed between 4 May (starting time 09:30 CEST) and 9 May 2018 (17:30). Meteorological data were measured and provided by the Institute of Physics, also located on the campus of the university. During the measurement period, the air masses came from north, northeast or east, and air mass composition can be expected to be especially influenced by the Frankfurt Rhine-Main Metropolitan Region with approximately 5.8 million inhabitants. Figure S9 in the Supplement shows $72 \mathrm{~h}$ backward trajectories of the air masses (every $24 \mathrm{~h}$ ) from 4 to 10 May 2018. The blank value for the seeded SOA experiments was used for the background correction, and values below the quantification limit were set to zero. Figure 8a shows the concentration ratios of TPPO to total TPP during the measurement period and Fig. $8 \mathrm{~b}$ the course of the particle-phase peroxide concentration. Actually, the smallest values of detected TPPO to total TPP shown in Fig. 8a lie very close to the estimated blank value level (red line). This indicates that blank values of ambient air measurements and the blank value from the seeded SOA experiments are almost identical. Values of the peroxide concentration above the limit of quantification (LOQ) (blue line) were only obtained during weekdays (5 May Saturday; 6 May Sunday) and in the daytime. The enhanced concentration during weekdays in daylight conditions indicates local sources of peroxides in combination with photochemistry, an observation that is in agreement with the result from previous peroxide measurements (Hua et al., 2008; Guo et al., 2014). However, due to highly variable emission sources directly outside the chemistry building, the selected measurement site was certainly not ideal for general studies about particle-phase peroxide chemistry. Nevertheless, this short proof-of-principle study demonstrates that peroxides in atmospheric aerosols can be detected in real time with the new ORD-AMS system. 

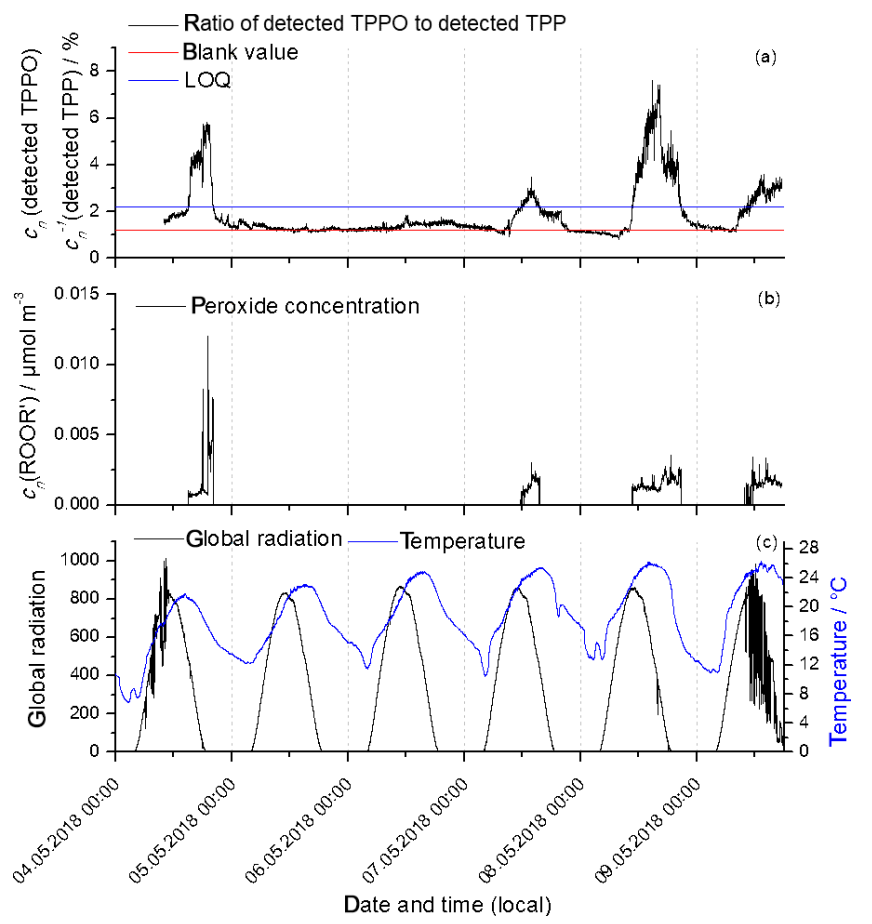

Figure 8. (a) Time series of the relative amount of detected TPPO to detected TPP, LOQ, and blank value,(b) diurnal variation in the estimated peroxide concentration, and (c) time series of the global radiation and temperature.

\section{Conclusions}

The real-time detection of peroxides by adding gaseous TPP to aerosol particles was successfully realized using an aerosol mass spectrometer in combination with a specifically designed online derivatization unit. The ozonolysis of $\alpha$ - and $\beta$ pinene in the presence of ammonium sulfate seed aerosol was used to demonstrate the potential of the analytical procedure. The results clearly show the conversion of TPP to TPPO and hence the presence of organic peroxides in biogenic SOA. Especially in the early phase of SOA formation the contribution of peroxides is exceptionally high (up to ca. $80 \%$ $v / v$ ). In addition, the time-resolved measurements show a rapid further reaction of the peroxides to non-peroxidic compounds indicative of consecutive reactions of the peroxides within the particle phase. The developed instrumental setup can also be used to receive particle size-resolved information about particle-phase peroxides. Again, the important role of organic peroxides in the early stages of particle formation, which was probably induced by very low-volatility multifunctional organic peroxides (HOMs), became clear. Finally, the new online redox derivatization method was successfully tested with ambient air outside the laboratory. The results presented here represent the first attempt to better characterize the role of organic peroxides in atmospheric aerosols. Future laboratory and field studies are certainly necessary to better understand the chemistry of peroxides in organic aerosols.

Data availability. The data obtained by ORD-AMS measurements from the SOA experiments are available on request from Marcel Weloe (maweloe@uni-mainz.de).

Supplement. The supplement related to this article is available online at: https://doi.org/10.5194/amt-13-5725-2020-supplement.

Author contributions. MW and TH designed the study. MW performed the experiments to develop ORD-AMS and performed the laboratory work, calibration and the data analysis. MW and TH examined the results, provided input on the data analysis and interpretation, and prepared the paper.

Competing interests. The authors declare that they have no conflict of interest.

Financial support. This research has been supported by the Deutsche Forschungsgemeinschaft (grant no. HO 1748/16-1, "Development and application of a real-time method for the determination of selected compound classes (especially organic peroxides) in atmospheric aerosol particles using an aerosol mass spectrometer (AMS)").

This open-access publication was funded by Johannes Gutenberg University Mainz.

Review statement. This paper was edited by Charles Brock and reviewed by two anonymous referees.

\section{References}

Allan, J. D., Alfarra, Bower, K. N., Williams, P. I., Gallagher, M. W., Jimenez, J. L., McDonald, A. G., Nemitz, E., Canagaratna, Jayne, J. T., Coe, H., and Worsnop: Quantitative sampling using an Aerodyne aerosol mass spectrometer - 2. Measurements of fine particulate chemical composition in two U.K. cities, J. Geophys. Res.-Atmos., 108, AAC 2-1-2-11, https://doi.org/10.1029/2002JD002359, 2003a.

Allan, J. D., Jimenez, J. L., Williams, P. I., Alfarra, Bower, K. N., Jayne, J. T., Coe, H., and Worsnop: Quantitative sampling using an Aerodyne aerosol mass spectrometer - 1. Techniques of data interpretation and error analysis, J. Geophys. Res.-Atmos., 108, AAC 1-1-1-10, https://doi.org/10.1029/2002JD002358, 2003b.

Bianchi, F., Trostl, J., Junninen, H., Frege, C., Henne, S., Hoyle, C. R., Molteni, U., Herrmann, E., Adamov, A., Bukowiecki, N., Chen, X., Duplissy, J., Gysel, M., Hutterli, M., Kangasluoma, J., Kontkanen, J., Kuerten, A., Manninen, H. E., Muench, S., Perakyla, O., Petaja, T., Rondo, L., Williamson, C., Weingartner, E., 
Curtius, J., Worsnop, D. R., Kulmala, M., Dommen, J., and Baltensperger, U.: New particle formation in the free troposphere: A question of chemistry and timing, Science, 352, 1109-1112, https://doi.org/10.1126/science.aad5456, 2016.

Bianchi, F., Garmash, O., He, X., Yan, C., Iyer, S., Rosendahl, I., Xu, Z., Rissanen, M. P., Riva, M., Taipale, R., Sarnela, N., Petäjä, T., Worsnop, D. R., Kulmala, M., Ehn, M., and Junninen, H.: The role of highly oxygenated molecules (HOMs) in determining the composition of ambient ions in the boreal forest, Atmos. Chem. Phys., 17, 13819-13831, https://doi.org/10.5194/acp-17-138192017, 2017.

Bianchi, F., Kurten, T., Riva, M., Mohr, C., Rissanen, M. P., Roldin, P., Berndt, T., Crounse, J. D., Wennberg, P. O., Mentel, T. F., Wildt, J., Junninen, H., Jokinen, T., Kulmala, M., Worsnop, D. R., Thornton, J. A., Donahue, N., Kjaergaard, H. G., and Ehn, M.: Highly Oxygenated Organic Molecules (HOM) from GasPhase Autoxidation Involving Peroxy Radicals: A Key Contributor to Atmospheric Aerosol, Chem. Rev., 119, 3472-3509, https://doi.org/10.1021/acs.chemrev.8b00395, 2019.

Bonn, B., von Kuhlmann, R., and Lawrence, M. G.: High contribution of biogenic hydroperoxides to secondary organic aerosol formation, Geophys. Res. Lett., 31, L10108, https://doi.org/10.1029/2003GL019172, 2004.

Brüggemann, M., Vogel, L. A., and Hoffmann, T.: Analysis of organic aerosols using a micro-orifice volatilization impactor (MOVI) coupled to an atmospheric-pressure chemical ionization mass spectrometer (APCI-MS), Eur. J. Mass Spectrom., 20, 3141, https://doi.org/10.1255/ejms.1260, 2014.

Brüggemann, M., Karu, E., Stelzer, T., and Hoffmann, T.: RealTime Analysis of Ambient Organic Aerosols Using Aerosol Flowing Atmospheric-Pressure Afterglow Mass Spectrometry (AeroFAPA-MS), Environ. Sci. Technol., 49, 5571-5578, https://doi.org/10.1021/es506186c, 2015.

Brüggemann, M., Karu, E., and Hoffmann, T.: Critical assessment of ionization patterns and applications of ambient desorption/ionization mass spectrometry using FAPA-MS, J. Mass Spectrom., 51, 141-149, https://doi.org/10.1002/jms.3733, 2016.

Brüggemann, M., Poulain, L., Held, A., Stelzer, T., Zuth, C., Richters, S., Mutzel, A., van Pinxteren, D., Inuma, Y., Katkevica, S., Rabe, R., Herrmann, H., and Hoffmann, T.: Realtime detection of highly oxidized organosulfates and BSOA marker compounds during the F-BEACh 2014 field study, Atmos. Chem. Phys., 17, 1453-1469, https://doi.org/10.5194/acp17-1453-2017, 2017.

Canagaratna, M. R., Jayne, J. T., Jimenez, J. L., Allan, J. D., Alfarra, M. R., Zhang, Q., Onasch, T. B., Drewnick, F., Coe, H., Middlebrook, A., Delia, A., Williams, L. R., Trimborn, A. M., Northway, M. J., DeCarlo, P. F., Kolb, C. E., Davidovits, P., and Worsnop, D. R.: Chemical and microphysical characterization of ambient aerosols with the aerodyne aerosol mass spectrometer, Mass Spectrom. Rev., 26, 185-222, https://doi.org/10.1002/mas.20115, 2007.

Chellamani, A. and Suresh, R.: Kinetics and mechanism of oxidation of triphenylphosphine by hydrogen peroxide, React. Kinet. Catal. Lett., 37, 501-505, 1988.

Claflin, M. S., Krechmer, J. E., Hu, W., Jimenez, J. L., and Ziemann, P. J.: Functional Group Composition of Secondary Organic Aerosol Formed from Ozonolysis of alpha-Pinene Under High VOC and Autoxida- tion Conditions, ACS Earth Space Chem., 2, 1196-1210, https://doi.org/10.1021/acsearthspacechem.8b00117, 2018.

Davies, A. G. and Feld, R.: 934. Organic peroxides. Part IX. A stereochemical study of the formation of alkyl hydroperoxides from hydrogen peroxide, J. Chem. Soc., 4637-4643, 1958.

DeCarlo, P. F., Slowik, J. G., Worsnop, D. R., Davidovits, P., and Jimenez, J. L.: Particle Morphology and Density Characterization by Combined Mobility and Aerodynamic Diameter Measurements. Part 1: Theory, Aerosol Sci. Tech., 38, 1185-1205, https://doi.org/10.1080/027868290903907, 2004.

DeCarlo, P. F., Kimmel, J. R., Trimborn, A., Northway, M. J., Jayne, J. T., Aiken, A. C., Gonin, M., Fuhrer, K., Horvath, T., Docherty, K. S., Worsnop, D. R., and Jimenez, J. L.: Field-deployable, high-resolution, time-of-flight aerosol mass spectrometer, Anal. Chem., 78, 8281-8289, https://doi.org/10.1021/ac061249n, 2006.

Docherty, K. S., Kumboonlert, K., Lee, I. J., and Ziemann, P. J.: Gas chromatography of trimethylsilyl derivatives of $\alpha$-methoxyalkyl hydroperoxides formed in alkene-O3 reactions, J. Chromatogr. A, 1029, 205-215, https://doi.org/10.1016/j.chroma.2003.12.014, 2004.

Docherty, K. S., Wu, W., Lim, Y. B., and Ziemann, P. J.: Contributions of Organic Peroxides to Secondary Aerosol Formed from Reactions of Monoterpenes with $\mathrm{O}_{3}$, Environ. Sci. Technol., 39, 4049-4059, https://doi.org/10.1021/es050228s, 2005.

Donahue, N. M., Robinson, A. L., Trump, E. R., Riipinen, I., and Kroll, J. H.: Volatility and Aging of Atmospheric Organic Aerosol, Top. Curr. Chem., 339, 97-143, https://doi.org/10.1007/128_2012_355, 2014.

Epstein, S. A., Blair, S. L., and Nizkorodov, S. A.: Direct Photolysis of a-Pinene Ozonolysis Secondary Organic Aerosol: Effect on Particle Mass and Peroxide Content, Environ. Sci. Technol., 48, 11251-11258, https://doi.org/10.1021/es502350u, 2014.

Fuller, S. J., Wragg, F. P. H., Nutter, J., and Kalberer, M.: Comparison of on-line and off-line methods to quantify reactive oxygen species (ROS) in atmospheric aerosols, Atmos. Environ., 92, 97 103, https://doi.org/10.1016/j.atmosenv.2014.04.006, 2014.

Gallimore, P. J., Giorio, C., Mahon, B. M., and Kalberer, M.: Online molecular characterisation of organic aerosols in an atmospheric chamber using extractive electrospray ionisation mass spectrometry, Atmos. Chem. Phys., 17, 14485-14500, https://doi.org/10.5194/acp-17-14485-2017, 2017.

Gotoh, N., Miyake, S., Takei, H., Sasaki, K., Okuda, S., Ishinaga, M., and Wada, S.: Simple Method for Measuring the Peroxide Value in a Colored Lipid, Food Anal. Methods, 4, 525-530, https://doi.org/10.1007/s12161-011-9193-5, 2011.

Guo, J., Tilgner, A., Yeung, C., Wang, Z., Louie, P. K. K., Luk, C. W. Y., Xu, Z., Yuan, C., Gao, Y., Poon, S., Herrmann, H., Lee, S., Lam, K. S., and Wang, T.: Atmospheric peroxides in a polluted subtropical environment: Seasonal variation, sources and sinks, and importance of heterogeneous processes, Environ. Sci. Technol., 48, 1443-1450, https://doi.org/10.1021/es403229x, 2014.

Hallquist, M., Wenger, J. C., Baltensperger, U., Rudich, Y., Simpson, D., Claeys, M., Dommen, J., Donahue, N. M., George, C., Goldstein, A. H., Hamilton, J. F., Herrmann, H., Hoffmann, T., Iinuma, Y., Jang, M., Jenkin, M. E., Jimenez, J. L., Kiendler-Scharr, A., Maenhaut, W., McFiggans, G., Mentel, Th. F., Monod, A., Prévôt, A. S. H., Seinfeld, J. H., Surratt, J. D., Szmigielski, R., and Wildt, J.: The formation, properties and im- 
pact of secondary organic aerosol: current and emerging issues, Atmos. Chem. Phys., 9, 5155-5236, https://doi.org/10.5194/acp9-5155-2009, 2009.

Hua, W., Chen, Z. M., Jie, C. Y., Kondo, Y., Hofzumahaus, A., Takegawa, N., Chang, C. C., Lu, K. D., Miyazaki, Y., Kita, K., Wang, H. L., Zhang, Y. H., and Hu, M.: Atmospheric hydrogen peroxide and organic hydroperoxides during PRIDE-PRD'06, China: their concentration, formation mechanism and contribution to secondary aerosols, Atmos. Chem. Phys., 8, 6755-6773, https://doi.org/10.5194/acp-8-6755-2008, 2008.

Hyde, A. M., Zultanski, S. L., Waldman, J. H., Zhong, Y.L., Shevlin, M., and Peng, F.: General Principles and Strategies for Salting-Out Informed by the Hofmeister Series, Org. Process Res. Dev., 21, 1355-1370, https://doi.org/10.1021/acs.oprd.7b00197, 2017.

Jarvie, A. W.P., Moore, C. G., and Skelton, D.: Reactions of some organic peroxides with triphenylphosphine and sodium dialkyl phosphites, J. Polym. Sci. A, 9, 3105-3114, 1971.

Jayanthi, S. and Koshore, K.: Reaction of polyperoxides with triphenylphosphine, J. Polym. Sci. B, 35, 1167-1172, 1997.

Jayne, J. T., Leard, D. C., Zhang, X. F., Davidovits, P., Smith, K. A., Kolb, C. E., and Worsnop, D. R.: Development of an aerosol mass spectrometer for size and composition analysis of submicron particles, Aerosol Sci. Tech., 33, 49-70, https://doi.org/10.1080/027868200410840, 2000.

Kahnt, A., Vermeylen, R., Iinuma, Y., Safi Shalamzari, M., Maenhaut, W., and Claeys, M.: High-molecular-weight esters in $\alpha$ pinene ozonolysis secondary organic aerosol: structural characterization and mechanistic proposal for their formation from highly oxygenated molecules, Atmos. Chem. Phys., 18, 84538467, https://doi.org/10.5194/acp-18-8453-2018, 2018.

Koop, T., Bookhold, J., Shiraiwa, M., and Pöschl, U.: Glass transition and phase state of organic compounds: Dependency on molecular properties and implications for secondary organic aerosols in the atmosphere, Phys. Chem. Chem. Pys., 13, 1923819255, https://doi.org/10.1039/c1cp22617g, 2011.

Krapf, M., El Haddad, I., Bruns, E. A., Molteni, U., Daellenbach, K. R., Prévôt, A. S. H., Baltensperger, U., and Dommen, J.: Labile Peroxides in Secondary Organic Aerosol, Chem., 1, 603616, https://doi.org/10.1016/j.chempr.2016.09.007, 2016.

Krawczyk, T. and Baj, S.: Review: Advances in the Determination of Peroxides by Optical and Spectroscopic Methods, Anal. Lett., 47, 2129-2147, https://doi.org/10.1080/00032719.2014.900781, 2014.

Kuwata, M., Zorn, S. R., and Martin, S. T.: Using elemental ratios to predict the density of organic material composed of carbon, hydrogen and oxygen, Environ. Sci. Technol., 46, 787-794, https://doi.org/10.1021/es202525q, 2012.

Lee, S.-H., Gordon, H., Yu, H., Lehtipalo, K., Haley, R., Li, Y., and Zhang, R.: New Particle Formation in the Atmosphere: From Molecular Clusters to Global Climate, J. Geophys. Res.-Atmos., 124, 7098-7146, https://doi.org/10.1029/2018JD029356, 2019.

Lelieveld, J., Butler, T. M., Crowley, J. N., Dillon, T. J., Fischer, H., Ganzeveld, L., Harder, H., Lawrence, M. G., Martinez, M., Taraborrelli, D., and Williams, J.: Atmospheric oxidation capacity sustained by a tropical forest, Nature, 452, 737-740, https://doi.org/10.1038/nature06870, 2008.

Li, H., Chen, Z., Huang, L., and Huang, D.: Organic peroxides' gasparticle partitioning and rapid heterogeneous decomposition on secondary organic aerosol, Atmos. Chem. Phys., 16, 1837-1848, https://doi.org/10.5194/acp-16-1837-2016, 2016.

Matthew, B. M., Middlebrook, A. M., and Onasch, T. B.: Collection Efficiencies in an Aerodyne Aerosol Mass Spectrometer as a Function of Particle Phase for Laboratory Generated Aerosols, Aerosol Sci. Tech., 42, 884-898, https://doi.org/10.1080/02786820802356797, 2008.

McNeill, V. F.: Atmospheric Aerosols: Clouds, Chemistry, and Climate, Annu. Rev. Chem. Biomol., 8, 427-444, https://doi.org/10.1146/annurev-chembioeng-060816-101538, 2017.

Mertes, P., Pfaffenberger, L., Dommen, J., Kalberer, M., and Baltensperger, U.: Development of a sensitive long path absorption photometer to quantify peroxides in aerosol particles (Peroxide-LOPAP), Atmos. Meas. Tech., 5, 2339-2348, https://doi.org/10.5194/amt-5-2339-2012, 2012.

Mochida, M., Katrib, Y., Jayne, J. T., Worsnop, D. R., and Martin, S. T.: The relative importance of competing pathways for the formation of high-molecular-weight peroxides in the ozonolysis of organic aerosol particles, Atmos. Chem. Phys., 6, 4851-4866, https://doi.org/10.5194/acp-6-4851-2006, 2006.

Mutzel, A., Rodigast, M., Iinuma, Y., Böge, O., and Herrmann, H.: An improved method for the quantification of SOA bound peroxides, Atmos. Environ., 67, 365-369, https://doi.org/10.1016/j.atmosenv.2012.11.012, 2013.

Nakamura, T. and Maeda, H.: A simple assay for lipid hydroperoxides based on triphenylphosphine oxidation and highperformance liquid chromatography, Lipids, 26, 765-768, https://doi.org/10.1007/BF02535628, 1991.

Porter, N. A., Logan, J., and Kontoyiannidou, V.: Preparation and purification of arachidonic acid hydroperoxides of biological importance, J. Org. Chem, 44, 3177-3181, 1979.

Pöschl, U.: Atmospheric aerosols: Composition, transformation, climate and health effects, Angew. Chem. Int. Ed., 44, 7520, https://doi.org/10.1002/anie.200501122, 2005.

Pratt, K. A. and Prather, K. A.: Mass spectrometry of atmospheric aerosolsuRecent developments and applications. Part I: Off-line mass spectrometry techniques, Mass Spectrom. Rev., 31, 1-16, https://doi.org/10.1002/mas.20322, 2012.

Reinnig, M.-C., Müller, L., Warnke, J., and Hoffmann, T.: Characterization of selected organic compound classes in secondary organic aerosol from biogenic VOCs by HPLC/MSn, Anal. Bioanal. Chem., 391, 171-182, https://doi.org/10.1007/s00216008-1964-5, 2008.

Reinnig, M.-C., Warnke, J., and Hoffmann, T.: Identification of organic hydroperoxides and hydroperoxy acids in secondary organic aerosol formed during the ozonolysis of different monoterpenes and sesquiterpenes by on-line analysis using atmospheric pressure chemical ionization ion trap mass spectrometry, Rapid Commun. Mass Sp., 23, 1735-1741, https://doi.org/10.1002/rcm.4065, 2009.

Riipinen, I., Pierce, J. R., Yli-Juuti, T., Nieminen, T., Häkkinen, S., Ehn, M., Junninen, H., Lehtipalo, K., Petäjä, T., Slowik, J., Chang, R., Shantz, N. C., Abbatt, J., Leaitch, W. R., Kerminen, V.-M., Worsnop, D. R., Pandis, S. N., Donahue, N. M., and Kulmala, M.: Organic condensation: a vital link connecting aerosol formation to cloud condensation nuclei (CCN) concentrations, Atmos. Chem. Phys., 11, 3865-3878, https://doi.org/10.5194/acp-11-3865-2011, 2011. 
Ruiz, A., Canada, M. J. A., and Lendl, B.: A rapid method for peroxide value determination in edible oils based on flow analysis with Fourier transform infrared spectroscopic detection, Analyst, 126, 242-246, https://doi.org/10.1039/b008688f, 2001.

Steimer, S. S., Kourtchev, I., and Kalberer, M.: Mass Spectrometry Characterization of Peroxycarboxylic Acids as Proxies for Reactive Oxygen Species and Highly Oxygenated Molecules in Atmospheric Aerosols, Anal. Chem., 89, 28732879, https://doi.org/10.1021/acs.analchem.6b04127, 2017.

Stein, R. and Slawson, V.: Spectrophotometric hydroperoxide determination by the use of triphenylphosphine, Anal. Chem., 35, 1008-1010, https://doi.org/10.1021/ac60201a027, 1963.

Thompson, A. M.: The Oxidizing Capacity of the Earth's Atmosphere - Probable Past and Future Changes, Science, 256, 1157$1165,1992$.

Thorenz, U. R., Kundel, M., Müller, L., and Hoffmann, T.: Generation of standard gas mixtures of halogenated, aliphatic, and aromatic compounds and prediction of the individual output rates based on molecular formula and boiling point, Anal. Bioanal. Chem., 404, 2177-2183, https://doi.org/10.1007/s00216-012$6202-5,2012$

Tobias, H. J. and Ziemann, P. J.: Kinetics of the gas-phase reactions of alcohols, aldehydes, carboxylic acids, and water with the C13 stabilized Criegee intermediate formed from ozonolysis of 1-tetradecene, J. Phys. Chem. A, 105, 6129-6135, 2002.

Tobias, H. J., Docherty, K. S., Beving, D. E., and Ziemann, P. J.: Effect of relative humidity on the chemical composition of secondary organic aerosol formed from reactions of 1tetradecene and O-3, Environ. Sci. Technol., 34, 2116-2125, https://doi.org/10.1021/es991057s, 2000.

Tong, H., Lakey, P. S. J., Arangio, A. M., Socorro, J., Shen, F., Lucas, K., Brune, W. H., Pöschl, U., and Shiraiwa, M.: Reactive Oxygen Species Formed by Secondary Organic Aerosols in Water and Surrogate Lung Fluid, Environ. Sci. Technol., 52, 1164211651, https://doi.org/10.1021/acs.est.8b03695, 2018.

Tröstl, J., Chuang, W. K., Gordon, H., Heinritzi, M., Yan, C., Molteni, U., Ahlm, L., Frege, C., Bianchi, F., Wagner, R., Simon, M., Lehtipalo, K., Williamson, C., Craven, J. S., Duplissy, J., Adamov, A., Almeida, J., Bernhammer, A.-K., Breitenlechner, M., Brilke, S., Dias, A., Ehrhart, S., Flagan, R. C., Franchin, A., Fuchs, C., Guida, R., Gysel, M., Hansel, A., Hoyle, C. R., Jokinen, T., Junninen, H., Kangasluoma, J., Keskinen, H., Kim, J., Krapf, M., Kürten, A., Laaksonen, A., Lawler, M., Leiminger, M., Mathot, S., Möhler, O., Nieminen, T., Onnela, A., Petäjä, T., Piel, F. M., Miettinen, P., Rissanen, M. P., Rondo, L., Sarnela, N., Schobesberger, S., Sengupta, K., Sipilä, M., Smith, J. N., Steiner, G., Tomè, A., Virtanen, A., Wagner, A. C., Weingartner, E., Wimmer, D., Winkler, P. M., Ye, P., Carslaw, K. S., Curtius, J., Dommen, J., Kirkby, J., Kulmala, M., Riipinen, I., Worsnop, D. R., Donahue, N. M., and Baltensperger, U.: The role of low-volatility organic compounds in initial particle growth in the atmosphere, Nature, 533, 527-531, https://doi.org/10.1038/nature18271, 2016.

Verma, V., Fang, T., Xu, L., Peltier, R. E., Russell, A. G., Ng, N. L., and Weber, R. J.: Organic aerosols associated with the generation of reactive oxygen species (ROS) by water-soluble $\mathrm{PM}_{2.5}$, Environ. Sci. Technol., 49, 4646-4656, https://doi.org/10.1021/es505577w, 2015.
Vogel, A. L., Äijälä, M., Brüggemann, M., Ehn, M., Junninen, H., Petäjä, T., Worsnop, D. R., Kulmala, M., Williams, J., and Hoffmann, T.: Online atmospheric pressure chemical ionization ion trap mass spectrometry (APCI-IT-MSn) for measuring organic acids in concentrated bulk aerosol - a laboratory and field study, Atmos. Meas. Tech., 6, 431-443, https://doi.org/10.5194/amt-6431-2013, 2013a.

Vogel, A. L., Äijälä, M., Corrigan, A. L., Junninen, H., Ehn, M., Petäjä, T., Worsnop, D. R., Kulmala, M., Russell, L. M., Williams, J., and Hoffmann, T.: In situ submicron organic aerosol characterization at a boreal forest research station during HUMPPA-COPEC 2010 using soft and hard ionization mass spectrometry, Atmos. Chem. Phys., 13, 10933-10950, https://doi.org/10.5194/acp-13-10933-2013, 2013 b.

Wang, N., Ma, T., Yu, X., Xu, L., and Zhang, R.: Determination of Peroxide Values of Edible Oils by Ultraviolet Spectrometric Method, Food Anal. Methods, 9, 1412-1417, https://doi.org/10.1007/s12161-015-0322-4, 2016.

Warscheid, B. and Hoffmann, T.: On-line measurements of a-pinene ozonolysis products using an atmospheric pressure chemical ionisation ion-trap mass spectrometer, Atmos. Environ., 35, 2927 2940, https://doi.org/10.1016/S1352-2310(00)00513-6, 2001a.

Warscheid, B. and Hoffmann, T.: Structural elucidation of monoterpene oxidation products by ion trap fragmentation using on-line atmospheric pressure chemical ionisation mass spectrometry in the negative ion mode, Rapid Commun. Mass Sp., 15, 22592272, https://doi.org/10.1002/rcm.504, 2001b.

Williams, D. H., Ward, R. S., and Cooks, R. G.: Mass spectrometry. XXIV. A study of the reactions induced in triphenylphosphine, triphenylphosphine oxide, and related substances upon electron impact, J. Am. Chem. Soc., 90, 966-972, https://doi.org/10.1021/ja01006a021, 1968.

Wragg, F. P. H., Fuller, S. J., Freshwater, R., Green, D. C., Kelly, F. J., and Kalberer, M.: An automated online instrument to quantify aerosol-bound reactive oxygen species (ROS) for ambient measurement and health-relevant aerosol studies, Atmos. Meas. Tech., 9, 4891-4900, https://doi.org/10.5194/amt-9-4891-2016, 2016.

Yatavelli, R. L. N., Mohr, C., Stark, H., Day, D. A., Thompson, S. L., Lopez-Hilfiker, F. D., Campuzano-Jost, P., Palm, B. B., Vogel, A. L., Hoffmann, T., Heikkinen, L., Aijala, M., Ng, N. L., Kimmel, J. R., Canagaratna, M.l.R., Ehn, M., Junninen, H., Cubison, M. J., Petaja, T., Kulmala, M., Jayne, J. T., Worsnop, D. R., and Jimenez, J. L.: Estimating the contribution of organic acids to northern hemispheric continental organic aerosol, Geophys. Res. Lett., 42, 6084-6090, https://doi.org/10.1002/2015GL064650, 2015.

Zhang, Q., Jimenez, J. L., Canagaratna, M. R., Ulbrich, I. M., Ng, N. L., Worsnop, D. R., and Sun, Y.: Understanding atmospheric organic aerosols via factor analysis of aerosol mass spectrometry: a review, Anal. Bioanal. Chem., 401, 3045-3067, https://doi.org/10.1007/s00216-011-5355-y, 2011.

Zhang, X., Lambe, A. T., Upshur, M. A., Brooks, W. A., Be, A. G., Thomson, R. J., Geiger, F. M., Surratt, J. D., Zhang, Z., Gold, A., Graf, S., Cubison, M. J., Groessl, M., Jayne, J. T., Worsnop, D. R., and Canagaratna, M. R.: Highly Oxygenated Multifunctional Compounds in alpha-Pinene Secondary Organic Aerosol, Environ. Sci. Technol., 51, 5932-5940, https://doi.org/10.1021/acs.est.6b06588, 2017. 
Zhao, R., Kenseth, C. M., Huang, Y., Dalleska, N. F., and Seinfeld, J. H.: Iodometry-Assisted Liquid Chromatography Electrospray Ionization Mass Spectrometry for Analysis of Organic Peroxides: An Application to Atmospheric Secondary Organic Aerosol, Environ. Sci. Technol., 52, 2108-2117, https://doi.org/10.1021/acs.est.7b04863, 2018.

Zhou, S., Rivera-Rios, J. C., Keutsch, F. N., and Abbatt, J. P. D.: Identification of organic hydroperoxides and peroxy acids using atmospheric pressure chemical ionizationtandem mass spectrometry (APCI-MS/MS): application to secondary organic aerosol, Atmos. Meas. Tech., 11, 3081-3089, https://doi.org/10.5194/amt-11-3081-2018, 2018.
Ziemann, P. J.: Evidence for low-volatility diacyl peroxides as a nucleating agent and major component of aerosol formed from reactions of O-3 with cyclohexene and homologous compounds, J. Phys. Chem. A, 106, 4390-4402, 2002.

Ziemann, P. J.: Formation of alkoxyhydroperoxy aldehydes and cyclic peroxyhemiacetals from reactions of cyclic alkenes with O-3 in the presence of alcohols, J. Phys. Chem. A, 107, 20482060, 2003.

Ziemann, P. J. and Atkinson, R.: Kinetics, products, and mechanisms of secondary organic aerosol formation, Chem. Soc. Rev., 41, 6582-6605, https://doi.org/10.1039/c2cs35122f, 2012. 